\title{
AN INTERNATIONAL COMPARATIVE STUDY OF THE INPUT-OUTPUT EFFICIENCY OF HUMAN RESOURCES OF SCIENCE AND TECHNOLOGY
}

\author{
Xie $\mathrm{YI}^{1}-$ Ran $\mathrm{RONG}^{2}$ \\ ${ }^{1}$ Economics and Business Administration, Chongqing University, Chongqing China, \\ 400030 No. 174, Shazheng Street, Shapingba District, Chongqing province, China. \\ E-mail:xieyi@cqu.edu.cn \\ ${ }^{2}$ School of Public Affair, Chongqing University, Chongqing China, No.174, Shazheng Street, \\ Shapingba District, Chongqing province 400030. \\ E-mail: ranrong@cqu.edu.cn (corresponding author)
}

\begin{abstract}
By using the input-output method and principal component analysis, this paper did a comparative research on the input-output efficiency of human resources of science and technology among the world's leading countries, and revealed the actual situation of the input-output efficiency of human resources of science and technology in our country. Among all these seven countries, the inputoutput efficiency of human resources of science and technology in Japan is the highest, and in China the lowest. There is a significant linear relationship between input and output. And finally, it put forward the thoughts and suggestions about improving the input and output efficiency of human resources of science and technology.
\end{abstract}

Keywords: science and technology, human resources, output efficiency, principal components, comparison

\section{INTRODUCTION}

Along with the strengthening of the reform and the deepening of the opening, the economic competition is becoming more and more intense. The competition for human resources of science and technology, as the main factor in production, is becoming more and more heat. To a certain extent, the competitiveness for human resources of science and technology determines the success or failure of economic competition. The higher the competitiveness of the human resources of science and technology, the stronger the economic competitiveness will be. The lower the competitiveness of the human resources of science and technology, the weaker the economic competitiveness will be. The core content of the competitiveness of 
human resources of science and technology is the input-output efficiency. Therefore, it is of great social meaning and realistic meaning to measure the inputoutput efficiency of human resources of science and technology of our country.

\section{LITERATURE REVIEW}

\subsection{The connotation of human resources of science and technology}

Many scholars have studied the connotation of competitiveness of human resources of science and technology (Luo 2010). But until now, it has not formed a convincible view. Here, we will not mention it in detail. This study thinks that the competitiveness of human resources of science and technology refers to the regional contribution ability of the human resources of science and technology itself when compared with other areas, the attractive advantages represented by the environments of developing talents as well as the comprehensive advantages formed by the potential talent cultivation (Poór et al. 2010). Lin et al. (2013) said that the human resources of science and technology of this paper refers to the staff of research and development in human resources of science and technology, hereinafter referred to as developers. It is referring to the systematic creative activities which are aiming at increasing the amount of knowledge and applying this knowledge to create new application system in the field of science and technology (Singh 2010). It includes basic research, applied research and experimental development. Internationally, it usually adopts the scale and intensity index of the activity of R\&D to reflect the scientific and technological strength and core competitiveness of a country (Yu 2007).

\subsection{The current research status of the input-output efficiency of human resources of science and technology}

Chi and Liang (2013) stated the development report of the comprehensive competitiveness of China's province and area economy (2005-2006), proposed the measurements such as the population growth rate (contrarian indicator), the proportion of population aged 15-64, illiteracy rates (contrarian indicator), the population proportion of the education level in the college, the average level of education, population health quality (life expectancy), human resource utilization (total employment population accounted for 15-64 years old population) and so on in its three-level index human resources competitiveness. Qian (2008) and Huang (2014) stated the competitiveness of the world's human resources of science and 
technology of 2006, classified four first level indicators, namely cultivate and develop, use and configuration, output and benefit, environment and policy, ten secondary indexes, and forty tertiary indicators. Wang and Du (2008) in the research on the status quo of the development and utilization of human resources of science and technology in our country discussed the problems of the development and utilization of human resources of science and technology, but not enough indepth and specific. Zhao (2006) in the discussion on the effective use of China's agricultural human resources of science and technology, concerned on the effective utilization of human resources of science and technology. Xin (2007) in the paper "The Preliminary research on the efficiency of human resources of science and technology" discussed the efficiency of human resources of science and technology without the empirical analysis.

The studies mentioned above have not made the systemic empirical research on the input-output efficiency of human resources of science and technology of our country. This paper absorbed the essence of the predecessors' research, combined with the understanding of the talent competitiveness, and to set up a set of index system to make a comprehensive and specialized research on the inputoutput efficiency of human resources of science and technology of our country.

\section{RESEARCH METHOD}

\subsection{Index computation part, this research uses Principal Component Analysis}

Principal component analysis is trying to reassemble the original indicators which are of certain relevance into a new set of comprehensive index that has nothing to do with each other. Namely it is the idea of dimension reduction. Multiple variables were divided into a handful of unrelated principal components, so that the internal structure of the data set can be described. Principal component analysis calculated by getting the eigenvalues and characteristic root of the covariance matrix or correlation coefficient matrix. According to the specified contribution rate, it calculated the relative gap of each candidate indicators in each sample, which is the basis of index selection. It extracted the indexes that have a relatively large gap in each sample, which will be taken as the elements of building a comprehensive evaluation index system, while the indexes which have a very small gap will be eliminated. In that way, we can get the main components which are gathering the main information of original random variables, but not related to each other to construct a comprehensive evaluation function. It cannot only exclude the subjective and objective factors when choosing the index and determining the weight, but also can eliminate the overlapping information between 
indexes and make quantitative analysis involve less variables and get more information. Thus it will be easier to seize the main contradiction and make an overall evaluation of the results uniquely, objectively and reasonably.

Principal component analysis can be used to calculate the relative number of multivariate samples, namely tectonic sample index, and can also sort the sample. Some of the index constructed by using principal component analysis is negative, which does not represent the true meaning of the utilization degree, but rather shows the region's relative position in the selected region, which is below the average level. Therefore, the principal component analysis is an ideal analysis tool. This study was conducted by using SPSS18.0 data statistics software.

\subsection{The calculation of output efficiency, we use the method of input and output}

The calculation formula of input-output analysis, which is commonly used by economics is: input and output ratio $=$ output $/$ input $\times 100 \%$. This paper adopts this formula to reflect the effective utilization of the organization group or individual. The bigger the ratio, the higher the effective utilization degree; the smaller the ratio, the lower the effective utilization degree.

\section{THE ESTABLISHMENT OF INDEX SYSTEM AND THE SOURCE OF DATA}

On the basis of scientific, systemic, comparability and operability principles, the index system of the input-output efficiency of human resources of science and technology of the present study includes the quantity of human resources of science and technology, the funds of scientific research and experimental development, granted patent of invention and the number of scientific papers and so on. These indicators are the data published by the national related department and international authority. The details are in Table 1. 
Table 1. The related original data of input-output of human resources of science and technology of the seven countries

\begin{tabular}{|c|c|c|c|c|c|c|c|c|}
\hline & & 节 & . & 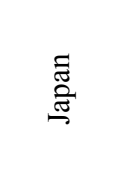 & 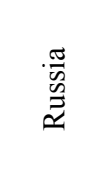 & 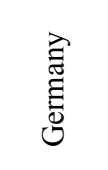 & 䓌 & 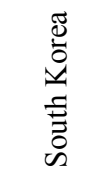 \\
\hline \multicolumn{2}{|c|}{$\begin{array}{l}\text { The human resources of } \\
\text { science and technology, } \\
\text { (scientific research and } \\
\text { experimental develop- } \\
\text { ment personnel) } \\
\text { (ten thousand) }\end{array}$} & 173.62 & $\begin{array}{c}274 \\
\text { (evaluated) }\end{array}$ & 93.79 & 91.23 & 49.39 & 33.37 & 26.94 \\
\hline \multicolumn{2}{|c|}{$\begin{array}{l}\text { The funds of } \\
\text { scientific research } \\
\text { and experimental } \\
\text { development (billion } \\
\text { dollar) }\end{array}$} & 488 & 3,688 & 1,508 & 145 & 842 & 503 & 337 \\
\hline \multirow{2}{*}{ 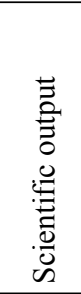 } & $\begin{array}{l}\text { granted patent of } \\
\text { invention (both at } \\
\text { home and abroad) } \\
\text { (piece) }\end{array}$ & 67,948 & 157,283 & 164,954 & 23,028 & 17,739 & 12,009 & 12,705 \\
\hline & $\begin{array}{l}\text { the number of } \\
\text { scientific papers } \\
\text { (ten thousand } \\
\text { piece) }\end{array}$ & 20.79 & 57.68 & 15.02 & 4.28 & 14.06 & 14.96 & 4.8 \\
\hline
\end{tabular}

Data source

1. International Statistical Yearbook 2009 complied by the National Bureau of Statistics of the People's Republic of China

2. The web site of the Ministry of Science and Technology

3. The web site of World Intellectual Property Organization http://www.wipo.int/ipstats/ en/statistics/patents/.

\section{THE EMPIRICAL ANALYSIS ON INPUT-OUTPUT EFFICIENCY OF HUMAN RESOURCES OF SCIENCE AND TECHNOLOGY}

\subsection{The calculation of input and output index}

1) Original data standardization transformation.

First, open the "analysis" menu of "statistical" of SPSS18.0 software (localization version), make use of "describing statistical analysis" to carry out the dimensionless processing of the original index data, and get the standardized variables. 
In this paper, the explanation about the output index calculation is made as the following.

2) The judgments of the correlation between indicators.

Use "factor analysis" option of "data reduction" in the menu of "analysis" to test the correlation of standardized variable. KMO test used to determine whether the factor analysis can be carried out. According to scholar Kaiser's (1974) point of view, if the value of KMO is less than 0.5 , it is not proper to carry out the factor analysis. This KMO value of this test is as low as 0.500 , which represents it is suitable to have factor analysis of this study (principal component analysis is one of the factor analysis). Bartlett ball test show whether the sample correlation matrix is the consistency matrix (identity matrix). The consistency matrix represented that variables are not related. Significance level value (Sig) is the result of this test. When the value is less than 0.05 , there may be a significant correlation among the variables. When this value is more than 0.10 , the correlation between variables is not strong. The data set is unfavorable for factor analysis. In this paper, when taking the ball test on the index of indicator, the value of Sig conforms to the requirements, which have passed the Bartlett ball test. So it is reasonable to adopt principal component analysis method, and the correlation coefficient matrix is omitted.

3) Determine the number of principal components.

Open the "data reduction" of the "analysis" menu, use the factor analysis to carry out the principal component analysis of the standard variable.

Table 2. Total variance explanation

\begin{tabular}{|c|c|c|c|c|c|c|}
\hline \multirow[b]{2}{*}{$\begin{array}{l}\text { Principle } \\
\text { component }\end{array}$} & \multicolumn{3}{|c|}{ The variance of principle components } & \multicolumn{3}{|c|}{ Extraction sums of squared loadings } \\
\hline & 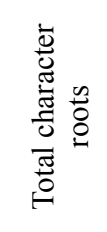 & 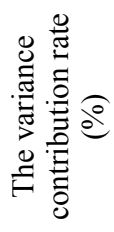 & 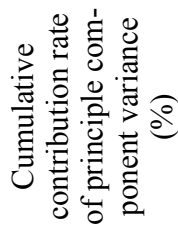 & 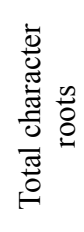 & 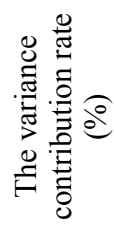 & 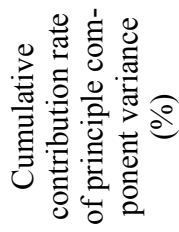 \\
\hline 1 & 1.787 & 89.336 & 89.336 & 1.787 & 89.336 & 89.336 \\
\hline 2 & .213 & 10.664 & 100.000 & & & \\
\hline
\end{tabular}

Extraction method: Principal Component Analysis

The selection principle of the number of principal component mainly includes two standards, the first one is the corresponding characteristic value, namely the first $J$ principal component whose variance is greater than 1 , and the second one is the contribution rate of the first principal component being more than $85 \%$. 
As for the first principle, to some extent the character value can be seen as the marker of principal component influence. If the characteristic value is less than 1 , it manifested that the explanation power of the principal component is less than the explanation power of directly importing an original variable. So the general eigenvalues is greater than 1 can be used as the inclusion criteria. For the second principle, the cumulative contribution rate reflects the first $m$ principal components, reflects more than $85 \%$ of the original information of the overall sample and basically reflects the general characteristics of the original data.

Table 2 shows that the eigenvalues of the first principal component is more than 1 , and the cumulative contribution rate is $89.336 \%$. And the cumulative contribution rate of the principal component meets the standard of the two main chosen components. Table 3 shows the index of human resources of science and technology and the funds index of scientific research and experimental development all have a high load on the first principal component, which shows that the first principal component reflects the most information of these two variables. So the author decided to use a new variable to replace the original two variables.

4) Identify and name the principal component expression.

Table 3. Component matrix (a) (principal component initial factor loading matrix)

\begin{tabular}{l|c}
\hline \multirow{2}{*}{ Standardized variables } & Component \\
\cline { 2 - 2 } & 1 \\
\hline $\begin{array}{l}Z \text { score (human resources of science } \\
\text { and technology) }\end{array}$ & .945 \\
\hline $\begin{array}{l}Z \text { score (the funds of scientific research } \\
\text { and experimental development) }\end{array}$ & .945 \\
\hline
\end{tabular}

Extraction method: Principal component analysis.

2 components are extracted

Using the data in Table 3 the main component of load matrix (each column represents the corresponding principal components and the corresponding variable correlation coefficient) divided the principal component corresponding to the open square root of the eigenvalue and got the correlation coefficient of each index in the main component. For example, the square root of the first characteristic value 1.787 is 1.337 . Then the first principal component is used in each value $(0.945,0.945)$ to be divided by 1.337 and will get the corresponding coefficient of each value in the first principal component (unit vector): $0.71,0.71$. So the principal component function of expression can be obtained (linear combination) as follows:

The principal component score of input $=0.71 * Z$ score (human resources of science and technology) $+0.71 * Z$ score (the funds of scientific research and experimental development). 
5) The determination of the evaluation formula of input comprehensive principal component (index).

The proportion of corresponding characteristic value of each principal component in the sum of overall eigenvalues extracted from principal components, as is shown in Table 2, was $89.336 \%$. With the above data as a weight to calculate the comprehensive evaluation model of principal components:

$$
F=\frac{\lambda_{1}}{\lambda_{1}+\lambda_{2}} F 1
$$

The $\lambda_{i}$ represents the eigenvalue of the principle component $F$. So the comprehensive evaluation function expression of principle components is:

Input comprehensive index $=$ the principal component score of input $* 0.89336$. In the same way, we can find out the output composite index, the human resources of science and technology input of each province and output index and their places are listed as seen in Table 4.

6) In the same way, we get the comprehensive principal component values of regional talent competitiveness, see Table 4.

\subsection{The calculation of the index of input-output efficiency}

According to the formula: input and output ratio $=$ earnings/input $\times 100 \%$, it is concluded that the following formula: the degree of the effective use of human resources of science and technology $=$ output index/input index $\times 100 \%$.

Specific results are shown in Table 4.

Table 4. Input and output index of human resources of science and technology, effective use and rankings of each country, 2013

\begin{tabular}{|c|c|c|c|c|c|c|}
\hline $\begin{array}{l}\stackrel{\mathscr{0}}{\Xi} \\
\text { 节 }\end{array}$ & 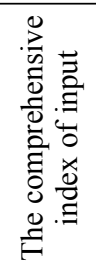 & 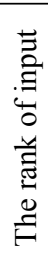 & 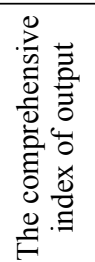 & 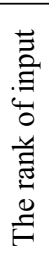 & 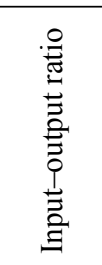 & 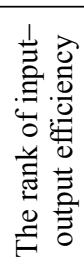 \\
\hline China & 0.18 & 2 & 0.10 & 3 & 54.00 & 7 \\
\hline America & 2.54 & 1 & 2.15 & 1 & 85.00 & 5 \\
\hline Japan & 0.14 & 3 & 0.54 & 2 & 399.00 & 1 \\
\hline Russia & -0.58 & 5 & -0.86 & 6 & 147.00 & 2 \\
\hline Germany & -0.52 & 4 & -0.51 & 4 & 98.00 & 3 \\
\hline Britain & -0.81 & 6 & -0.52 & 5 & 64.00 & 6 \\
\hline South Korea & -0.94 & 7 & -0.91 & 7 & 97.00 & 4 \\
\hline
\end{tabular}




\subsection{The input-output efficiency analysis}

According to the sorting table, we can see that the science and technology human resources input index of Japan is the third, the output index is the second, and the output benefit is the highest. While the input and output index in the United States are the highest, the output benefit is the fifth. As to China, the input is ranking second, the output is ranking third, but the output benefit came last. Russia's human resources of science and technology input and output are both low, but the input and output efficiency is ranking second.

\section{CONCLUSIONS}

Through the empirical analysis, we can find that:

First, there are many differences among the degree of effective use of human resources of science and technology of different countries. Second, it is not the more input and output of the human resources of science and technology, the higher the input-output efficiency of human resources of science and technology. There should be a reasonable proportion between them.

By the monadic regression analysis, there is a significant linear correlation between the input index and output index. The Pearson correlation test was at the level of 0.01 (double side), the correlation coefficient reached 0.974 , so the regression equation is: output index $=(7.248-17)+0.880$ input index. Because $(7.248-$ 17 ) is constant and the value is very small, so it can be neglected, so the regression equation is simplified as:

The output index $=0.880$ input index. Third, the total number of the input and output of human resources of science and technology are both higher, but the input-output efficiency is very low, which means that we have a lot of waste, inefficiency, and need to take effective measures to change and finally step onto the road of high production and lower consumption.

\section{CONCLUSION AND SUGGESTIONS}

Our country is trying to achieve sustained, rapid and healthy economic development. Developing the enthusiasm, initiative and creativity of human resources of science and technology, improving the effective use and benefit of resources, reducing waste have become more and more important. Therefore, aiming at the problems found out by this study, the author proposes the following suggestions: 
1. Strengthening the quantity and quality of human resources of science and technology.

The increase of the competitiveness of human resources of science and technology requires a large number of talents. But the most important is that output and production efficiency of talents are high. Therefore, on the one hand, we need to improve the quality of education and national quality, and cultivate more human resources, on the other hand, we also need to attract human resources by different ways.

2. Improve the effective use of human resources of science and technology. The degree of the effective use of human resources of science and technology is closely related to its input-output efficiency. Therefore it is an effective way to improve the efficiency of the input-output efficiency by improving the effective use of human resources of science and technology with created conditions.

3. Do the best on the "hope project" of the development of potential talents.

The development of potential human resources of science and technology in fact is to develop the "hematopoietic capacity" of regional human resources. Seeing all the developed countries throughout the world, they not only introduce the talents but also all attach importance to its own cultivation of talents. Therefore, China must increase investment in talent training, and should not be "once the emperor, once a courtier", and devoted to the so-called "achievements".

4. Improve the technology content of production; go to the way of high efficiency and low consumption.

The production of a country should be based on a moderate scale, improve the quality of technical content, get the quality and benefit from the technology, take the road of green development, and not blindly expand the scale of production.

\section{ACKNOWLEDGEMENTS}

Project No. 12XGL020 supported by the National Social Science Foundation of China (12XGL020)

Project No. CQDXWL-2013-Z004, CDJSK 11016 and CDJRC 10010012 supported by the Fundamental Research Funds for the Central Universities

Project No. 70902030, 71372137 supported by the National Nature Science Foundation of China $(70902030,71372137)$ 


\section{REFERENCES}

Chi, S-C.S. and Liang, S-G. (2013). When do subordinates' emotion-regulation strategies matter? Abusive supervision, subordinates' emotional exhaustion, and work withdrawal. The Leadership Quarterly, 24(1), 125-137.

Huang, S.P. (2014). A study on the relations among the human resource management system, organizational commitment and business performance. Acta Oeconomica, 64(Supplement 2), $275-288$.

Lin, W., Wang, L. and Chen, S. (2013). Abusive supervision and employee well-being: The moderating effect of power distance orientation. Applied Psychology: An International Review, 62, 308-329.

Lu, L., Kao, S-F., Siu, O-L. and Lu, C-Q. (2010). Work stressors, Chinese coping strategies, and job performance in Greater China. International Journal of Psychology, 45, 294-302.

Luo, J. (2010). Research on path and strategy of optimizing the personnel structure in tertiary industry. Economic Forum, 48(1),155-157.

Poór, J., Engle, A. and Gross, A. (2010). Human resource management practices of large multinational firms in Hungary, 1988-2005. Acta Oeconomica, 60(4), 427-460.

Qian, D. (2008). The competitiveness of world's human resources of science and technology . Science and Technology of China BBS, (2), 131-142.

Wang, F. and Du, Y-P. (2008). The current situation of the development and utilization of human resources of science and technology in our country and the improvement research. Journal of Network of Wealth, 9, 230-246.

Xin, M. (2007). The primary study of human resources of science and technology. Journal of Information about Science and Technology, (13), 131-149.

$\mathrm{Yu}, \mathrm{Ye}(2007)$. China's human resource of science and technology in the world. Journal of Quality Research, (12), 133-148.

Zhao, R. (2006). The discussion about the effective use of China's agricultural human resources of science and technology. China's Agriculture Bulletin, (3), 45-61. 